\title{
Fabrication, Optoelectronic and Photocatalytic Properties of Some Composite Oxide Nanostructures
}

\author{
C. W. Zou and W. Gao ${ }^{\dagger}$ \\ Department of Chemical and Material Engineering, School of Engineering, The University of Auckland, Private Bag 92019, \\ Auckland, New Zealand
}

Received January 20 2010, Accepted January 292010

\begin{abstract}
This is an overview paper reporting our most recent work on processing and microstructure of nano-structured oxides and their photoluminescence and photo-catalysis properties. Zinc oxide and related transition metal oxides such as vanadium pentoxide and titanium dioxide were produced by a combination of magnetron sputtering, hydrothermal growth and atmosphere controlled heat treatment. Special morphology and microstructure were created including nanorods arrays, core-brushes, nano-lollipops and multilayers with very large surface area. These structures showed special properties such as much enhanced photoluminescence and chemical reactivity. The photo-catalytic properties have also been promoted significantly. It is believed that two factors contributed to the high reactivity: the large surface area and the interaction between different oxides. The transition metal oxides with different band gaps have much enhanced photoluminescence under laser stimulation. Use of these complex oxide structures as electrodes can also improve the energy conversion efficiency of solar cells. The mixed oxide complex may provide a promising way to high-efficiency photo emitting materials and photo-catalysts.
\end{abstract}

Keywords: Zinc oxide, Vanadium pentoxide, Titanium dioxide, Processing of composite oxides, Nanostructure, Photoluminescence, Photocatalysis

\section{INTRODUCTION}

Functional one-dimensional metallic oxides have attracted much attention because of their potential use in electronic, optical and spintronic devices [1]-[4]. Among them, zinc oxide ( $\mathrm{nnO})$, titanium dioxide $\left(\mathrm{TiO}_{2}\right)$, and vanadium pentoxide $\left(\mathrm{V}_{2} \mathrm{O}_{5}\right)$ nanostructures including nanowires, nanobelts and nanorods have been extensively studied due to their special electronic, chemical and optical properties [5]-[11]. Incorporating these metallic oxide materials into an integrated structure with nanoscale dimension is of great interest because the resulting hierarchical nanostructures often possess much large surface areas and improved physical and chemical properties, providing potential applications for sensing, light emission and photocatalysis [12]-[16].

It is known that $\mathrm{ZnO}$ material can be made with the most diverse and abundant configurations of nanostructures such

\footnotetext{
† Author to whom corresponding should be addressed: electronic mail:w.gao@auckland.ac.nz
}

as quantum dots, rods, wires, belts, springs, bows, helices and prisms [12]-[22]. Accordingly, ZnO based composite nanostructures are easily built up combined with other metallic oxides [23]-[25]. The outside metallic oxides layers can be deposited onto the surfaces of the $\mathrm{ZnO}$ nanostructure substrates by different ways including sputtering methods or vapor deposition, and then the so-called "hierarchical nanostructures" are formed. Some interesting configurations or morphologies can be obtained for these combined nanomaterials. Special and improved optical or electronic properties are often reported [14], [26]-[29]. Currently, the typical composite nanomaterials such as core-shell nanostructure formed by the inside nanorods with the outside covered layers. Examples including $\mathrm{TiO}_{2} / \mathrm{ZnO}, \mathrm{ZnO} / \mathrm{MgO}$ and $\mathrm{ZnO} / \mathrm{Er}_{2} \mathrm{O}_{3}$ core-shell structures have been fabricated [30]-[33]. Increase in light emission or efficiency enhancement for dye-sensitized solar cells based on those core-shell structures are observed, which certainly proves that these types of composite nanostructures have enhanced optical and electronic properties that may have practical applications. 
In the current review, we summarize our recent work on the $\mathrm{ZnO}$ nanorod based composite nanostructures including the fabrication processes, microstructure characterization and the related photocatalytic applications. We would also like to discuss the current research status on these composite nanostructures and demonstrate the promising photocatalytic applications through the way of incorporating these metallic oxide materials into an integrated structure.

\section{FABRICATIONS AND MICROSTRUCTURE}

The microstructure and properties of metallic oxide are very sensitive to the processing techniques and parameters. In our study, we mainly use $\mathrm{ZnO}$ nanorods as the nanotemplate; some other oxides such as $\mathrm{V}_{2} \mathrm{O}_{5}$ and $\mathrm{TiO}_{2}$ were then deposited onto $\mathrm{ZnO}$ nanorods by magnetron sputtering to form controllable composite structure [34], [35]. Combined with annealing treatment under controlled atmosphere at suitable temperature, novel hierarchical nanostructures can be obtained, with much improved optical or electronic properties than simple $\mathrm{ZnO}, \mathrm{V}_{2} \mathrm{O}_{5}$, or $\mathrm{TiO}_{2}$ nanostructures.

\subsection{Simple nanorods array template}

For the composite nanostructure preparation, $\mathrm{ZnO}$ nanorods and $\mathrm{V}_{2} \mathrm{O}_{5}$ nanorods are selected as the basic templates since these two metallic oxides have stable characters; and the nanorods structure can be prepared in a well controllable and effective way [34]-[38].

\subsection{1 $\mathrm{ZnO}$ nanorods array}

Aligned $\mathrm{ZnO}$ nanorods have been successfully synthesized by catalyst-assisted vapor phase synthesis and catalyst-free metal-organic chemical vapor deposition [39]-[43]. We use a relatively simple method, template-assisted hydrothermal growth based on wet chemical reaction [35], which provide a low-cost, low-temperature, and environmental friendly way for highly ordered $\mathrm{ZnO}$ nanorods array preparation.

The template-assisted hydrothermal growth method includes two steps: first a thin $\mathrm{ZnO}$ seeds layer $(\sim 100 \mathrm{~nm})$ was sputtered onto glass or silicon substrates, and then the coated substrates were suspended vertically in a sealable glass bottle filled with aqueous solutions of zinc nitrate and hexamethylenetetramine for $\mathrm{ZnO}$ growth. Diluted nitride acid or ammonia hydroxide solution was used to adjust the $\mathrm{pH}$ values. The sealed bottle was put into an oven at $95^{\circ} \mathrm{C}$ for several hours for the $\mathrm{ZnO}$ nanorods to grow. $\mathrm{ZnO}$ nanorods with different surface distribution densities can be successfully obtained by controlling the initial $\mathrm{pH}$ value of the growth solution, as shown in Fig. 1. The ordered $\mathrm{ZnO}$ nanorods have a preferential growth direction of [002], and the rod formed is a single crystal. Furthermore, the morphologies of the nanorods array including the length, radius and orientation can also be controlled to certain extent by adjusting the solution concentration, thickness of the seed layer, growth temperature and growth time. Obviously, this facile preparation method provides a feasible way for the basic $\mathrm{ZnO}$ nanorods
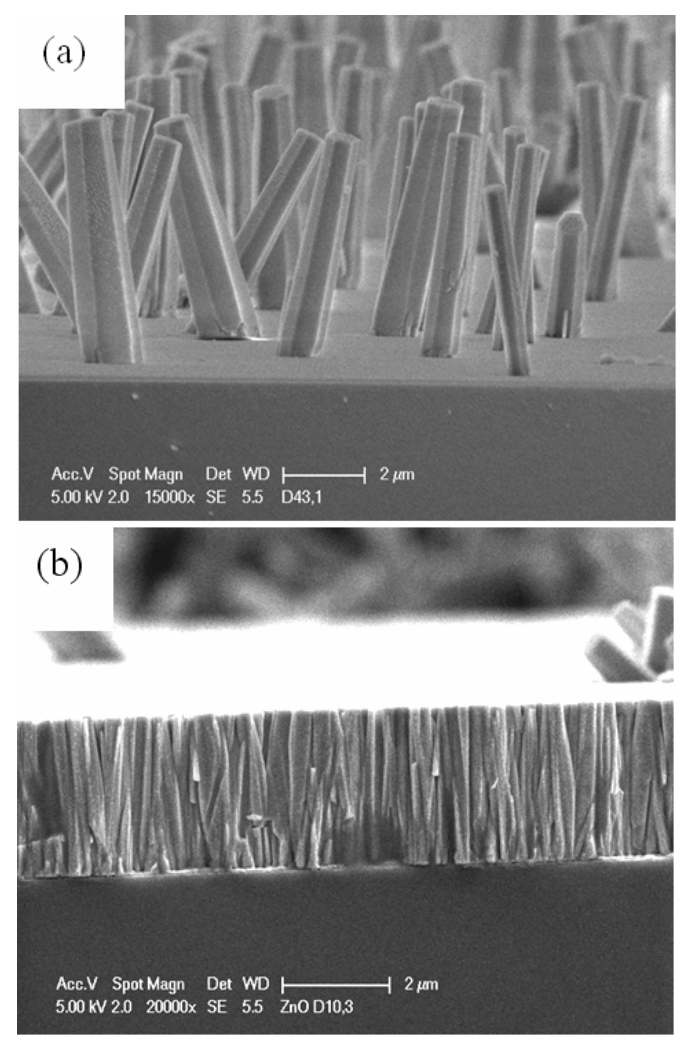

Fig. 1. Zinc oxide nanorod arrays with different surface distribution densities prepared by low-temperature template assisted growth in solutions: (a) sparse and (b) dense rods grown in solutions with low and high $\mathrm{pH}$ values, respectively.

array preparation, thus supplying good templates for the following oxide composite structure fabrication.

\subsection{2 $\beta-\mathrm{V}_{2} \mathrm{O}_{5}$ nanorods}

Vanadium oxides have several stoichiometries including $\mathrm{VO}, \mathrm{V}_{2} \mathrm{O}_{3}, \mathrm{VO}_{2}$, and $\mathrm{V}_{2} \mathrm{O}_{5}$, among which vanadium pentoxide, $\mathrm{V}_{2} \mathrm{O}_{5}$, is the most stable oxide and show semiconductor property with an energy gap of $\sim 2.2 \mathrm{eV}$ at room temperature [44][49]. Due to its layered structure and special characteristics including chemical sensing, multi-colored electrochromism and photochromism, $\mathrm{V}_{2} \mathrm{O}_{5}$ has attracted much interest, and has been considered to be a promising material for applications in Li-ion battery electrode, optical-electrical switches and color memory devices [50]-[54].

Several approaches have been reported to synthesize nanostructured vanadium oxides including hydrothermal method, sol-gel method and vapor phase epitaxy growth method [37], [55]-[60]. Recently an alternative approach to produce single crystalline $\beta-\mathrm{V}_{2} \mathrm{O}_{5}$ nanorods has been developed in our labs [36], [61]. The sputtered amorphous $\mathrm{V}_{2} \mathrm{O}_{5}$ films on glass substrate showed a temperature-sensitive crystallization behavior and transferred to $\beta-\mathrm{V}_{2} \mathrm{O}_{5}$ nanorods or $\beta$ phase nanoslices with highly oriented structure after an annealing in $\mathrm{O}_{2}$ atmosphere at $500-550^{\circ} \mathrm{C}$ as shown in Fig. 2. The related X-ray diffraction (XRD) spectra indicate that the $\beta-\mathrm{V}_{2} \mathrm{O}_{5}$ nanorods obtained after an annealing at $500^{\circ} \mathrm{C}$ possess a highly ordered crystal structure. 
(A)

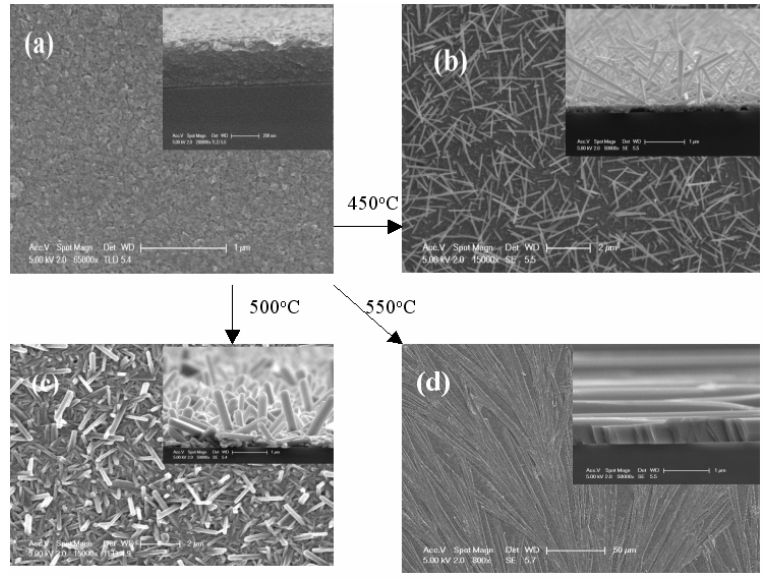

(B)

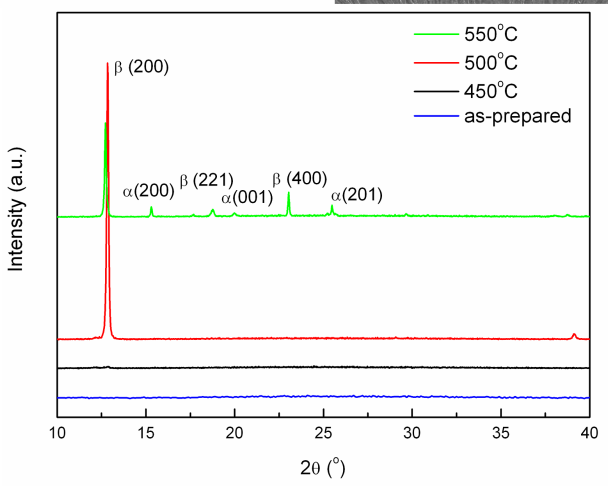

Fig. 2. (A) The temperature sensitive crystallization process of vanadium pentoxide $\left(\mathrm{V}_{2} \mathrm{O}_{5}\right)$ : (a) the as-prepared amorphous $\mathrm{V}_{2} \mathrm{O}_{5}$ film; (b) annealed at $450^{\circ} \mathrm{C}$; (c) $\beta-\mathrm{V}_{2} \mathrm{O}_{5}$ nanorods formed after annealing at $500^{\circ} \mathrm{C}$ and (d) flat-lying nanoslices formed at $550^{\circ} \mathrm{C}$. The inserts show the related cross-section morphology for each sample. (B) X-ray difffraction patterns for the as-prepared and annealed samples.

Based on this temperature sensitive crystallization, $\mathrm{V}_{2} \mathrm{O}_{5}$ can be made to complex composite nanostructures. Interesting morphologies and hierarchical structures can be achieved after suitable annealing treatment, which will be shown below.

\subsection{Composite nanostructures}

By using the $\mathrm{ZnO}$ nanorods array as the basic template, different composite nanostructures can be effectively fabricated with large-scale production. In the following part, we introduce one of these fabrication progresses: producing $\mathrm{ZnO}$ based composite nanostructures combined with magnetron sputter method.

\subsection{1 $\mathrm{ZnO} / \mathrm{TiO}_{2}$ core-brush array}

$\mathrm{ZnO}$ and $\mathrm{TiO}_{2}$ nanowires have been extensively studied due to their potential use in solar cells and as photocatalysts [62][65]. The principles of these applications are quite similar: based on their light absorption, light-electron conversion and electron transportation properties. To enhance the light conversion efficiency and improve the performance of the solar cells or photocatalysts, it is necessary to achieve high external quantum yields across a broad visible light spectrum, to

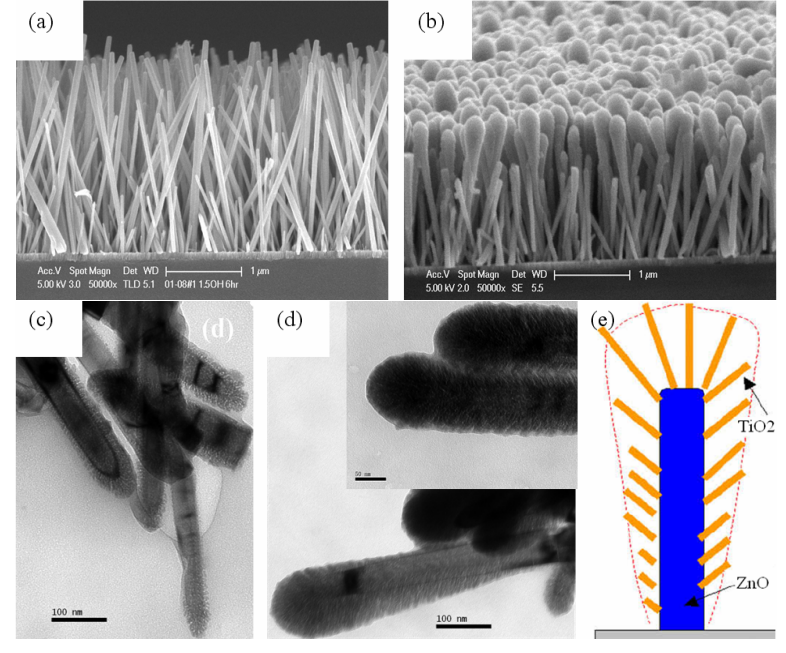

Fig. 3. (a) Zinc oxide $(\mathrm{ZnO})$ nanorods array before titanium dioxide $\left(\mathrm{TiO}_{2}\right.$ ) deposition; (b) $\mathrm{ZnO} / \mathrm{TiO}_{2}$ bottlebrush nanostructures after 90 min deposition; (c) transmission electron microscopy images of $\mathrm{ZnO} / \mathrm{TiO}_{2}$ bottlebrush nanostructures with deposition time of $60 \mathrm{~min}$ and $90 \mathrm{~min}$; (d) the insert shows the enlarged image; and (e) schematics for the formation of $\mathrm{ZnO} / \mathrm{TiO} 2$ nanobrush.

increase the diffusion length of electrons within the nanocrystalline materials, and to increase the speed of the electron transport process [30]. As $\mathrm{TiO}_{2}$ and $\mathrm{ZnO}$ materials have different band gaps, their composites should cover a broader light absorption spectrum than the individuals can cover. Furthermore, it is known that the electron transport rate in $\mathrm{ZnO}$ nanowires is much faster than in $\mathrm{TiO}_{2}$ due to its higher electrical conductivity [66].

Based on the above factors, $\mathrm{ZnO} / \mathrm{TiO}_{2}$ composites, or coreshell nanostructures, have attracted much attention for solar cell and photocatalyst applications [11], [30], [66]-[68]. Currently we use two-step process to prepare $\mathrm{ZnO} / \mathrm{TiO}_{2}$ heterostructured bottle brush. Firstly, $\mathrm{ZnO}$ nanorods arrays are synthesised on glass substrates by the seed-assisted low temperature $\left(95^{\circ} \mathrm{C}\right)$ hydrothermal method as described previously [35]. $\mathrm{TiO}_{2}$ layers are then deposited on the top and sidesurfaces of $\mathrm{ZnO}$ nanorods by using magnetron sputtering with low deposition rate at room temperature. Pure $\mathrm{TiO}_{2}$ is used as the target and $\mathrm{Ar}$ as the working gas. The deposition time is controlled to be $30 \mathrm{~min}$ and $60 \mathrm{~min}$.

The obtained $\mathrm{ZnO} / \mathrm{TiO}_{2}$ nano-bottlebrush structures are shown in Fig. 3. It is clear that a $\mathrm{TiO}_{2}$ shell has been coated on the surfaces of $\mathrm{ZnO}$ nanorods, and the initial $\mathrm{ZnO}$ nanorods became the torch-shaped microstructure from the scanning electron microscopy (SEM) images. To further investigate the bottlebrush nanostructure, transmission electron microscopy (TEM) was used for more detailed microstructure of the obtained bottlebrushes. It can be seen that fine $\mathrm{TiO}_{2}$ nanowires are just like "hairs," and orderly grown on the top and side surfaces of $\mathrm{ZnO}$ nanorods. With longer deposition time, the $\mathrm{TiO}_{2}$ hairs grow longer on the $\mathrm{ZnO}$ nanorods surfaces. Finally, the initially bare $\mathrm{ZnO}$ nanorods became bottlebrush-like nanostructures. A schematic drawing of formation mechanism is shown in Fig. 3(e).

The crystal structures of the $\mathrm{ZnO} / \mathrm{TiO}_{2}$ bottlebrush nanostructures were investigated by X-ray diffraction, which shows 
(a)
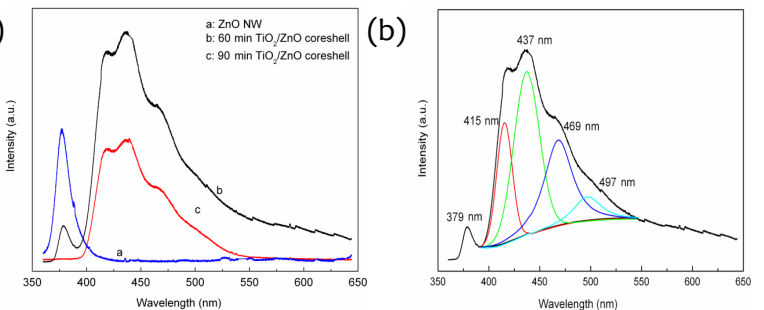

(c)
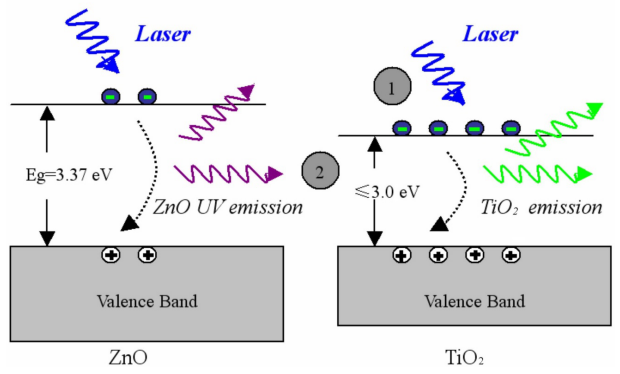

$\mathrm{TiO}_{2}$

Fig. 4. (a) Photoluminescence ( $\mathrm{PL}$ ) spectra at room temperature from zinc oxide $(\mathrm{ZnO})$ nanorods sample and $\mathrm{ZnO} /$ titanium dioxide $\left(\mathrm{TiO}_{2}\right)$ bottlebrush samples with deposition time of 60 and $90 \mathrm{~min}$; (b) the curve fitting of the PL spectra for the sample of 60 min deposition; (c) schematic illustration of the enhanced PL process from the $\mathrm{ZnO} / \mathrm{TiO}_{2}$ bottlebrush nanostructures with resonant effect. Two excitation channels are shown in the figure.

the basic $\mathrm{ZnO}$ nanorods array has good crystalline structure with the preferred oriented growth direction of [002], while the outside-covered $\mathrm{TiO}_{2}$ layer shows several peaks with the rutile (110) dominant peak. From the current XRD, however, it is difficult to determine the individual $\mathrm{TiO}_{2}$ nanowires deposited on the $\mathrm{ZnO}$ nanorods are polycrystalline or single crystalline, though they look much like single crystals. Further highresolution TEM (HR-TEM) is needed to confirm the microstructure and crystallinity of the covered $\mathrm{TiO}_{2}$ nanowires.

The growth mechanism for the $\mathrm{TiO}_{2}$ nanowire coating is suggested to be in two stages. The first stage is that the initial nucleation of $\mathrm{TiO}_{2}$ nanocrystals on the $\mathrm{ZnO}$ nanorods surfaces. For this stage, it should be attributed to the heterogeneous nucleation, in which the interfacial energetics plays a key role. After the nucleation stage, the $\mathrm{TiO}_{2}$ nanowires will growth along the preferential [110] direction of rutile phase, which is the second stage of $\mathrm{TiO}_{2}$ nanowire formation. For the second stage, surface energetics should dominate the crystal growth mechanism to minimize the surface energy [20].

It should be noted that the relatively low depositing rate under a low sputter power in the magnetron sputter is another key point that favors the $\mathrm{TiO}_{2}$ nanowires growth. If a high sputtering power and high bias voltage were applied, the $\mathrm{Ti}^{4+}$ and $\mathrm{O}^{2-}$ ions will have much higher kinetic energy, which tends to form an amorphous $\mathrm{TiO}_{2}$ film at room temperature.

The composite $\mathrm{ZnO} / \mathrm{TiO}_{2}$ nano-bottlebrush structures exhibited a much enhanced optical properties as shown in Fig. 4(a). The photoluminescence ( $\mathrm{PL}$ ) emission for the initial $\mathrm{ZnO}$ nanorods show a strong UV light emission peak at $\sim 379 \mathrm{~nm}$ (curve a), and no other visible light emission peaks can be seen, evidence of the good crystalline quality of the $\mathrm{ZnO}$ nanorods prepared by hydrothermal method. After $\mathrm{TiO}_{2}$ deposi- tion for 60 minutes, the PL peak from $\mathrm{ZnO}$ at the UV range reduced dramatically, and the $\mathrm{TiO}_{2}$ related $\mathrm{PL}$ peaks in the visible light range appeared (curve b). After 90 minutes deposition, the $\mathrm{ZnO}$ related PL peak at $379 \mathrm{~nm}$ disappeared entirely, and the $\mathrm{TiO}_{2}$-related $\mathrm{PL}$ peaks became weaker (curve c) compared to the sample with 60 minutes deposition. The detailed $\mathrm{PL}$ analysis of the 60 minutes deposited $\mathrm{ZnO} / \mathrm{TiO}_{2}$ bottlebrush sample is shown in Fig. 4(b). The peak at $379 \mathrm{~nm}$ is the UV peak from the $\mathrm{ZnO}$ nanorods and the other peaks at $415 \mathrm{~nm}, 437 \mathrm{~nm}, 469 \mathrm{~nm}$ and $497 \mathrm{~nm}$ are from the $\mathrm{TiO}_{2}$ nanowires. The peak at $415 \mathrm{~nm}$ is likely to come from the selftrapped excitons localized at $\mathrm{TiO}_{6}$ octahedral sites, and the other longer wave peaks could be attributed to the oxygen vacancies on the surface area of $\mathrm{TiO}_{2}$ nanowires [69]-[71].

From the different PL spectra, it is interesting to discuss the origin of the enhancement of light emission from the integrated composite nanostructures. Obviously, the disappearance of the $\mathrm{ZnO}$ related ultraviolet (UV) peak for the bottlebrush of 90 minutes should be due to the relatively thick and dense $\mathrm{TiO}_{2}$ nanowire layer, thus the laser source has low penetration intensity to excite the inner $\mathrm{ZnO}$ nanorods. For the 60 minutes deposited $\mathrm{ZnO} / \mathrm{TiO}_{2}$ bottlebrush sample, $\mathrm{PL}$ came from both the core part of $\mathrm{ZnO}$ and the shell part of $\mathrm{TiO}_{2}$ hairs by the laser excitation. Thus both the UV peak from $\mathrm{ZnO}$ and peaks from $\mathrm{TiO}_{2}$ appeared in the $\mathrm{PL}$ spectra. At the same time, a coupling mechanism may have taken place between the $\mathrm{ZnO}$ and $\mathrm{TiO}_{2}$ nanostructures: Some UV photons from $\mathrm{ZnO}$ may have been absorbed by the outside $\mathrm{TiO}_{2}$ nanowires, and the outside $\mathrm{TiO}_{2}$ hairs were excited by both the laser light and UV emission from the inner $\mathrm{ZnO}$ nanorods, as illustrated by the schematic in Fig. 4(c). These two excitation mechanisms may have formed a so-called resonant effect for the PL process, and may have been the reason that the intensity of the $\mathrm{TiO}_{2}$-related $\mathrm{PL}$ peak has been enhanced significantly [34].

\subsection{2 $\mathrm{ZnO} / \mathrm{V}_{2} \mathrm{O}_{5}$ bilayer}

Our experimental results indicated that $\mathrm{V}_{2} \mathrm{O}_{5}$ films prepared by magnetron sputtering on glass substrates have temperature sensitive crystallization behavior within a narrow annealing temperature range from $450^{\circ} \mathrm{C}$ to $550^{\circ} \mathrm{C}$ [36], [61]. Especially, when annealed at $500^{\circ} \mathrm{C}$, highly ordered $\beta-\mathrm{V}_{2} \mathrm{O}_{5}$ nanorods will form.

According to the previous research, $\mathrm{V}_{2} \mathrm{O}_{5}$ material always shows visible light $\mathrm{PL}$, and the emission intensity strongly depends on their microstructure [72]-[74]. However, $\mathrm{V}_{2} \mathrm{O}_{5}$ has hardly been considered as a candidate for light emitting due to the unsatisfying emission intensity. Recent papers reported that GaN based light emission diodes capped by $\mathrm{ZnO}$ layer or nanostructures showed enhanced light emission, which may provide an effective way to increase the light emission efficiency of luminescence materials [75], [76]. Thus it is interesting to investigate the light emission of $\mathrm{V}_{2} \mathrm{O}_{5} / \mathrm{ZnO}$ bi-layer composites in an effort to obtain enhanced light emission from $\mathrm{ZnO}$ incorporated $\mathrm{V}_{2} \mathrm{O}_{5}$ nanostructures.

$\mathrm{V}_{2} \mathrm{O}_{5}$ films capped by a thin $\mathrm{ZnO}$ layer were prepared by magnetron sputtering method at room temperature. The microstructure of the post-annealed samples was characterized by SEM and XRD as shown in Fig. 5. It can be observed 

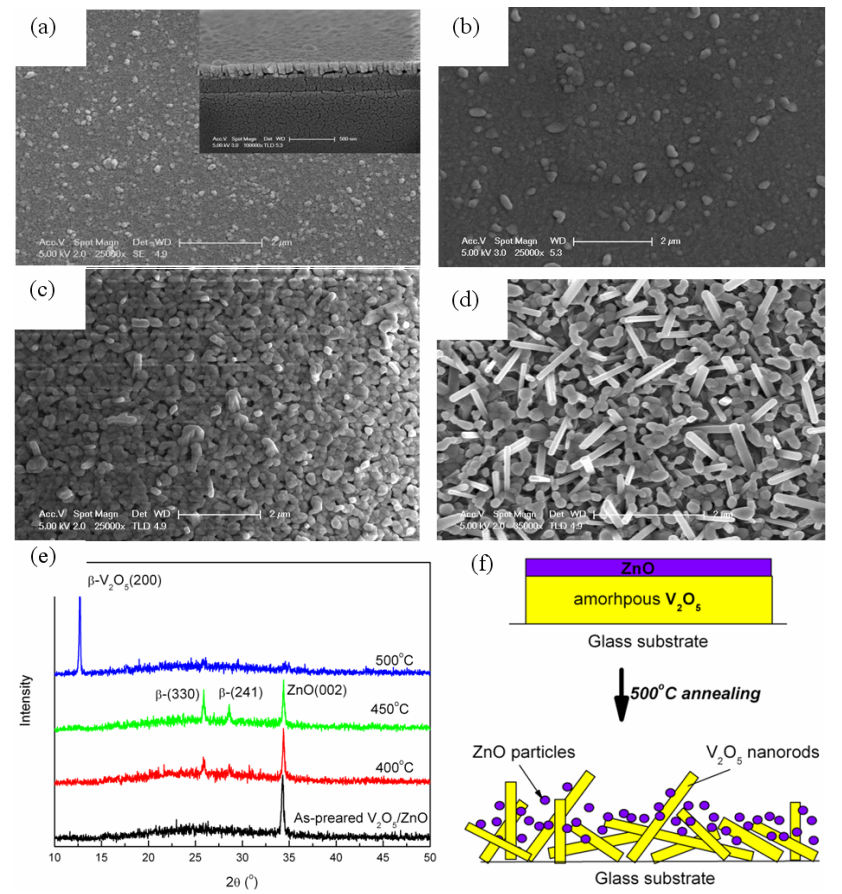

Fig. 5. (a) Surface morphology of as-deposited vanadium pentoxide/zinc oxide $\left(\mathrm{V}_{2} \mathrm{O}_{5} / \mathrm{ZnO}\right)$ samples, the insert shows the cross-section image; (b) sample annealed at $400^{\circ} \mathrm{C}$; (c) sample annealed at $450^{\circ} \mathrm{C}$; (d) sample annealed at $500^{\circ} \mathrm{C}$; (e) X-ray diffraction spectra for $\mathrm{V}_{2} \mathrm{O}_{5} / \mathrm{ZnO}$ bi-layer composite samples before and after annealing with different temperatures; and ( $f$ ) a schematic drawing to show the changes of the microstructure.

that the as-deposited $\mathrm{V}_{2} \mathrm{O}_{5} / \mathrm{ZnO}$ sample has a quite smooth surface comprising compact particles with small grain size. The cross-section (the insert image) shows a clear interface between the $\mathrm{V}_{2} \mathrm{O}_{5}$ amorphous film $(\sim 350 \mathrm{~nm})$ and the capped ZnO layer ( $120 \mathrm{~nm})$.

After an annealing in $\mathrm{O}_{2}$ ambience at $400^{\circ} \mathrm{C}$, the $\mathrm{ZnO}$ small grains grew up and became larger particles at the top surface as shown in Fig. 5(b). When the annealing temperature increases to $450^{\circ} \mathrm{C}$, the surface grains grew further larger, Fig. 5(c). After an annealing at $500^{\circ} \mathrm{C}$, the samples show very different surface microstructures as in Fig. 5(d). Clusters and nanorods with porous structures clearly appear on the sample surface. Combined with the XRD spectra in Fig. 5(e), it can be seen that those nanorods (slices) grew from the interstices of the porous particles are $\beta-\mathrm{V}_{2} \mathrm{O}_{5}$ crystals. The annealed composite samples here show similar $\beta-\mathrm{V}_{2} \mathrm{O}_{5}$ nanorods comparing with those pure $\mathrm{V}_{2} \mathrm{O}_{5}$ films after annealed at $500^{\circ} \mathrm{C}$, since $\mathrm{V}_{2} \mathrm{O}_{5}$ compound always show strong temperature sensitive crystallization. At the same time, the top-layer continuous $\mathrm{ZnO}$ thin film transferred into porous particles. This situation is understandable considering the interfacial interaction such as the effects of strain and stress during the annealing process. The capped $\mathrm{ZnO}$ layer on $\mathrm{V}_{2} \mathrm{O}_{5}$ films tends to depress the crystallization process of $\mathrm{V}_{2} \mathrm{O}_{5}$ to form standing $\beta-\mathrm{V}_{2} \mathrm{O}_{5}$ nanorods. However, due to the strong temperature sensitive crystallization behavior, the crystallization of $\mathrm{V}_{2} \mathrm{O}_{5}$ may not be suppressed by the covered $\mathrm{ZnO}$ layer. As a competition reaction, the annealed $\mathrm{V}_{2} \mathrm{O}_{5}$ became ordered $\beta$ $\mathrm{V}_{2} \mathrm{O}_{5}$ nanorods and the continuous $\mathrm{ZnO}$ layer was tore into
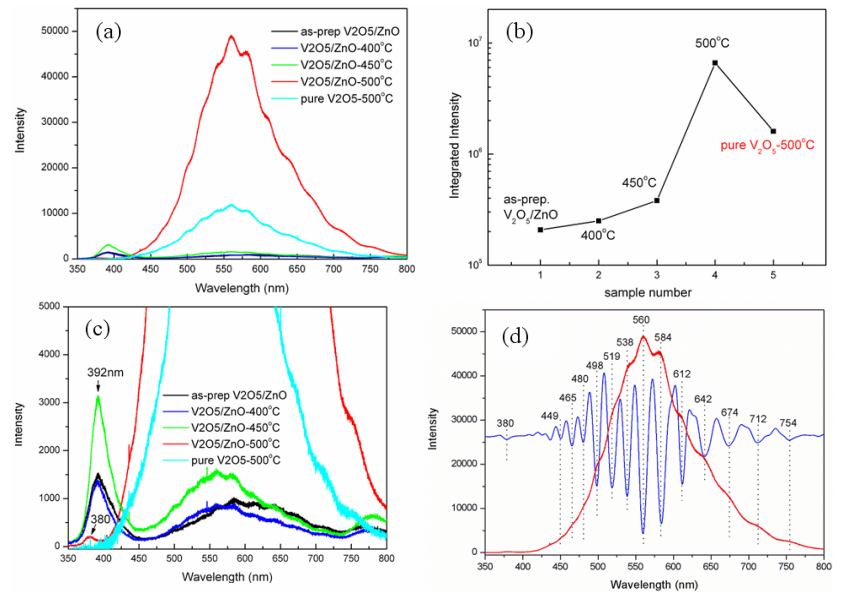

Fig. 6. (a) and (c) Photoluminescence (PL) spectra for vanadium pentoxide/zinc oxide $\left(\mathrm{V}_{2} \mathrm{O}_{5} / \mathrm{ZnO}\right)$ samples, (b) the integrated intensities for the different samples, and (d) PL spectrum and corresponding second-derivative spectrum for a $\mathrm{V}_{2} \mathrm{O}_{5} / \mathrm{ZnO}$ sample annealed at $500^{\circ} \mathrm{C}$.

porous particles because of the interfacial strain. The porous $\mathrm{ZnO}$ particles were therefore dispersed to cover the $\beta-\mathrm{V}_{2} \mathrm{O}_{5}$ nanorods surfaces with an amorphous-like state. This process is schematically illustrated in Fig. 5(f). The XRD spectra showing the absence of $\mathrm{ZnO}$ related diffraction peaks give direct evidence for the above mechanism. Furthermore, the change of surface morphology for the samples annealed at $500^{\circ} \mathrm{C}$ is unlikely caused by the solid-state reaction between $\mathrm{V}_{2} \mathrm{O}_{5}$ and $\mathrm{ZnO}$ according to the binary phase diagram of $\mathrm{V}_{2} \mathrm{O}_{5}$ and $\mathrm{ZnO}$ [77].

The optoelectronic properties of $\mathrm{V}_{2} \mathrm{O}_{5} / \mathrm{ZnO}$ samples are characterized by $\mathrm{PL}$ at room temperature with a $325 \mathrm{~nm} \mathrm{He}-\mathrm{Cd}$ laser source. From Fig. 6(a), it is clear that the broad green light emission from the $\mathrm{V}_{2} \mathrm{O}_{5} / \mathrm{ZnO}$ sample and pure $\mathrm{V}_{2} \mathrm{O}_{5}$ sample after an annealing at $500^{\circ} \mathrm{C}$ is much stronger than other samples. A great enhancement for the light emission has been observed, especially for the $\mathrm{V}_{2} \mathrm{O}_{5} / \mathrm{ZnO}$ sample after annealing. The main peak is centered at $560 \mathrm{~nm}$, which is quite consistent with the reported band gap of crystal $\mathrm{V}_{2} \mathrm{O}_{5}$ of 2.2 $\mathrm{eV}$, confirming that the enhanced light emission should be mainly generated from the near band edge emission of crystal $\mathrm{V}_{2} \mathrm{O}_{5}$ nanostructures.

Figure 6(b) shows that annealing temperature has a very strong effect on the integrated intensity of light emission. It can be seen that the intensity enhancement is not significant when the annealing temperature is below $500^{\circ} \mathrm{C}$. After an annealing at $500^{\circ} \mathrm{C}$, however, the visible light emission increased dramatically. The enhancement for the pure $\mathrm{V}_{2} \mathrm{O}_{5}$ sample is $\sim 8$ times, while for $\mathrm{V}_{2} \mathrm{O}_{5} / \mathrm{ZnO}$ composite sample, the enhancement reaches $\sim 25$ times compared with the as prepared samples. This tremendous enhancement was attributed to the coupling between $\mathrm{V}_{2} \mathrm{O}_{5}$ nanorods and $\mathrm{ZnO}$ nanoparticles as well as the improved $\mathrm{V}_{2} \mathrm{O}_{5}$ crystallinity. From the SEM images of Fig. 5(d) and the schematics of Fig. 5(f), the originally continuous $\mathrm{ZnO}$ layer becomes individual (amorphous) particles that surrounded the $\mathrm{V}_{2} \mathrm{O}_{5}$ nanorods, forming a porous surface. As a result, the $\mathrm{V}_{2} \mathrm{O}_{5}$ nanorods well embed into those amorphous $\mathrm{ZnO}$ nanoparticles. Thus, the 
absorption for the excitation laser beam is much enhanced for the annealed composite sample via the coupling with the surrounding $\mathrm{ZnO}$ particles. Accordingly, the light emission from $\mathrm{V}_{2} \mathrm{O}_{5}$ will be greatly improved, as the UV emission from ZnO particles ( $\sim 3.4 \mathrm{eV}$ band gap) acts as another exciting source, added to the laser source to excite $\mathrm{V}_{2} \mathrm{O}_{5}$ nanorods, resulting in a much higher light emission efficiency for the composite $\mathrm{V}_{2} \mathrm{O}_{5} / \mathrm{ZnO}$ sample compared to the pure $\mathrm{V}_{2} \mathrm{O}_{5}$ or ZnO.

More detailed PL information is shown in Fig. 6(c). It can be seen that the $\mathrm{ZnO}$ related peaks at $\sim 392 \mathrm{~nm}$ is quite clear for the as-prepared $\mathrm{V}_{2} \mathrm{O}_{5} / \mathrm{ZnO}$ sample and the annealed samples below $500^{\circ} \mathrm{C}$. The enhanced $\mathrm{ZnO}$ peak for the sample annealed at $450^{\circ} \mathrm{C}$ should be due to the improved $\mathrm{ZnO}$ crystallinity. The $\mathrm{V}_{2} \mathrm{O}_{5} / \mathrm{ZnO}$ samples annealed at $500^{\circ} \mathrm{C}$ show decreased ZnO UV-peak and prominent blue shift to $380 \mathrm{~nm}$. The obvious near-band-edge blue shift of $\mathrm{ZnO}$ is considered to come from the phase and microstructure variation of $\mathrm{ZnO}$ layer after annealing, since the blue shift of ZnO UV emission was reported to be associated with small particle size and amorphous state [78], [79]. Obviously, the observed blue shift of ZnO UV peak also provides a strong support for the above explanation that the capped $\mathrm{ZnO}$ layer becomes porous particles due to the interfacial strain after an annealing at $500^{\circ} \mathrm{C}$.

Figure $6(\mathrm{~d})$ shows the $\mathrm{PL}$ spectra for the $\mathrm{V}_{2} \mathrm{O}_{5} / \mathrm{ZnO}$ sample annealed at $500^{\circ} \mathrm{C}$ with the corresponding second-derivative $\mathrm{PL}$ spectrum. Vibrational PL is clearly observed, characterizing a fine structure. The related peaks positions are labeled in the figure. According to previous literatures [80], [81], the vibrational fine structures are usually caused by the $\mathrm{V}=\mathrm{O}$ vanadyl group involved in a tetrahedral coordination. Previous studies reported that the fine features of PL spectra for $\mathrm{V}_{2} \mathrm{O}_{5}$ were prominent at low temperature experiment. For the current samples, vibrational fine structures can be observed clearly at room temperature, which should be due to the high ordered structure of $\mathrm{V}_{2} \mathrm{O}_{5}$ nanorods.

$\mathrm{V}_{2} \mathrm{O}_{5} / \mathrm{ZnO}$ composite nanostructures show greatly enhanced visible light emission after an annealing at suitable temperature due to the coupling between $\mathrm{V}_{2} \mathrm{O}_{5}$ nanorods and $\mathrm{ZnO}$ nanoparticles. The improved $\mathrm{V}_{2} \mathrm{O}_{5}$ crystallinity after suitable annealing may have been another reason. This composite structure with significantly enhanced light emission suggests its potential applications as new luminescence or phosphorescence materials. Further work on other similar oxide pairs may discover more promising light emission systems.

\subsection{3 $\mathrm{ZnO} / \mathrm{V}_{2} \mathrm{O}_{5}$ nano-“lollipop” array}

$\mathrm{ZnO} / \mathrm{N}_{2} \mathrm{O}_{5}$ bi-layers showed strong photoemission due to the temperature sensitive crystallization of $\mathrm{V}_{2} \mathrm{O}_{5}$ material and interaction of $\mathrm{V}_{2} \mathrm{O}_{5}$ with $\mathrm{ZnO}$. What will happen if the $\mathrm{ZnO}$ layer is replaced by $\mathrm{ZnO}$ rods? This session reports our work on the $\mathrm{ZnO}$ nanorods based $\mathrm{ZnO} / \mathrm{N}_{2} \mathrm{O}_{5}$ composite nanostructures and their properties. $\mathrm{ZnO}$ nanorods arrays were synthesised on glass substrates $(25 \mathrm{~mm} \times 10 \mathrm{~mm})$ by using the seedassisted low temperature $\left(95^{\circ} \mathrm{C}\right)$ hydrothermal method described above [35]. $\mathrm{V}_{2} \mathrm{O}_{5}$ shell layer was then deposited onto the surfaces of $\mathrm{ZnO}$ nanorods by using magnetron sputter at room temperature. High purity $\mathrm{V}_{2} \mathrm{O}_{5}(\sim 99.9 \%)$ was used as the
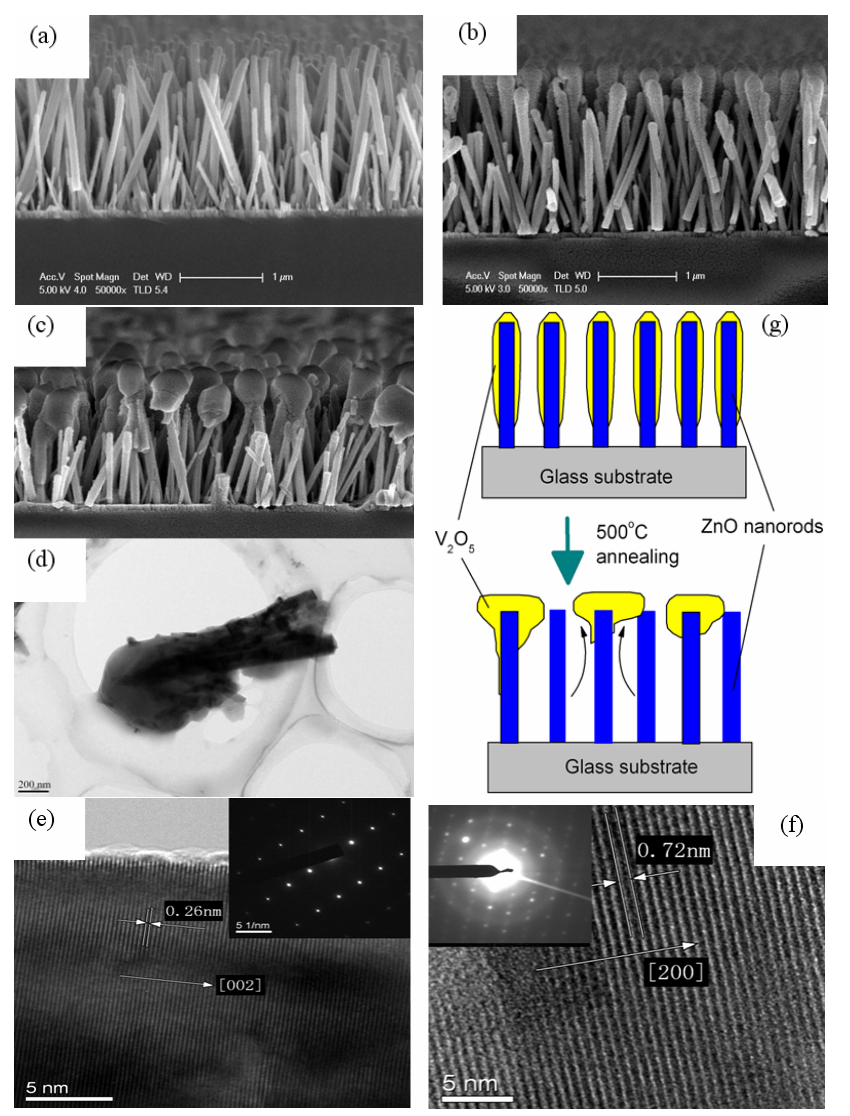

Fig. 7. (a) Scanning electron microscopy cross-section and top surface images for as-prepared zinc oxide ( $\mathrm{ZnO}$ ) nanorods array; (b) $\mathrm{ZnO}$ nanorods array covered by vanadium pentoxide $\left(\mathrm{V}_{2} \mathrm{O}_{5}\right)$ layer with deposition time of 60 minutes; (c) cross-section sample of the annealed $\mathrm{ZnO} / \mathrm{V}_{2} \mathrm{O}_{5}$ composite nanorods arrays; (d) transmission electron microscopy (TEM) image for the annealed ZnO/ $\mathrm{N}_{2} \mathrm{O}_{5}$ composite nanorods; (e) The high-resolution TEM (HRTEM) images for the ZnO nanorods as the stem; (f) HR-TEM images for the $\mathrm{V}_{2} \mathrm{O}_{5}$ crystal ball as the head; $(G)$ a schematic to show the growth process of the "lollipop" structure during annealing.

target and $\mathrm{Ar}$ as the working gas. The base vacuum of the sputtering chamber was lower than $4 \times 10^{-6}$ torr. The working pressure and the flux were controlled to be $10 \mathrm{mtorr}$ and 10 sccm, respectively. After above preparation, the samples were annealed under oxygen ambience at different temperatures.

The morphologies of $\mathrm{ZnO} / \mathrm{V}_{2} \mathrm{O}_{5}$ composite nanorods arrays are shown in Fig. 7. It can be observed that a $\mathrm{V}_{2} \mathrm{O}_{5}$ shell has been coated on the top and side surfaces of $\mathrm{ZnO}$ nanorods. After deposition, the initial $\mathrm{ZnO}$ nanorods became a torchshaped core-shell structure according to the SEM images. After an annealing at $500^{\circ} \mathrm{C}$ in oxygen ambience, the $\mathrm{ZnO} / \mathrm{V}_{2} \mathrm{O}_{5}$ core-shells changed their morphologies to the interesting heterogeneous nano-lollipops array, as shown in Fig. $7(\mathrm{c})$. Comparing with the microstructures of as-deposited $\mathrm{ZnO} / \mathrm{V}_{2} \mathrm{O}_{5}$ core-shell samples, the annealed samples show heterogeneous nano-lollipops shape with the top heads of $\mathrm{V}_{2} \mathrm{O}_{5}$ crystal balls and the stems of $\mathrm{ZnO}$ nanorods.

Figures $7(d)-(e)$ shows the TEM images for the $\mathrm{ZnO} / \mathrm{N}_{2} \mathrm{O}_{5}$ nanolollipop structure. The lattice image for the $\mathrm{ZnO}$ nanorods as the stem can be clearly observed in HR-TEM image, 
which indicates the growth direction of the $\mathrm{ZnO}$ nanorods prepared by hydrothermal method. The lattice structure of $\mathrm{V}_{2} \mathrm{O}_{5}$ crystal is revealed in Fig. $7(\mathrm{f})$. The lattice distance is about $0.72 \mathrm{~nm}$, which is close to the (200) inter-plane distance of $\mathrm{V}_{2} \mathrm{O}_{5}$ single crystal.

Figure $7(\mathrm{~g})$ illustrates the microstructure change from the as-deposited samples to the annealed composite samples. It is believed that this phenomenon is related to the temperature-sensitive crystallization behavior of $\mathrm{V}_{2} \mathrm{O}_{5}$ material which was discussed in details in one of our previous reports [61]. The surface diffusion of $\mathrm{V}_{2} \mathrm{O}_{5}$ at $500^{\circ} \mathrm{C}$ may also play an important role in the formation of nano-lollipops array based on $\mathrm{ZnO} / \mathrm{V}_{2} \mathrm{O}_{5}$ core-shell structure. The initially covered $\mathrm{V}_{2} \mathrm{O}_{5}$ particles with amorphous state have diffused along the surface of $\mathrm{ZnO}$ nanorods, and aggregated together during the heat treatment process, forming ball-shape $\mathrm{V}_{2} \mathrm{O}_{5}$ nanocrystals on the top of the $\mathrm{ZnO}$ nanorods.

\section{PHOTOCATALYTIC APPLICATIONS}

It can be observed that the metallic oxides composite nanostructures including $\mathrm{TiO}_{2} / \mathrm{ZnO}$ and $\mathrm{ZnO} / \mathrm{N}_{2} \mathrm{O}_{5}$ nanostructures show much enhanced PL emission as well as broadened $\mathrm{PL}$ spectra. Accordingly, these composite nanostructures may have potentials for photocatalysis or dye sensitized solar cell applications due to the broadened spectra, which covers the spectra band from ultraviolet to visible light band.

\section{1 $\mathrm{ZnO} / \mathrm{TiO}_{2}$ composite nano-brush for decomposi- tion of Bromo-Pyrogallol red dye}

$\mathrm{ZnO} / \mathrm{TiO}_{2}$ composite nano-brush show enhanced photo emission for the $\mathrm{TiO}_{2}$ covered "brush-hair," which should have good photocatalytic ability. Here the photocatalytic performance of as formed $\mathrm{ZnO} / \mathrm{TiO}_{2}$ composite nano-brush was studied by decomposition of Bromo-Pyrogallol red ( $\mathrm{Br}$ PGR) dye under UV-radiation.

The decomposition tests of $\mathrm{Br}-\mathrm{PGR}$ dye aqueous solution were conducted as follows: $1 \times 1 \mathrm{~cm}$ of the $\mathrm{ZnO} / \mathrm{TiO}_{2}$ composite sample was immersed into $2 \mathrm{ml} \mathrm{Br-PGR}$ solution with a concentration of $0.02 \mathrm{mg} / \mathrm{L}$ in a photoreaction chamber. A mercury tube lamp $(25 \mathrm{~W})$ was used as a UV irradiation source with centre wavelength at $254 \mathrm{~nm}$. The lamp was located 10 $\mathrm{cm}$ away from the reaction chamber. Before exposure the sample to the UV light, the dye solution with catalyst slide was stirred thoroughly in the dark for 30 minutes to reach the adsorption equilibrium of the dye on the catalyst. The change of Br-PGR concentration in accordance with the irradiation time was measured using a UV-Vis spectrophotometer (Agilent 8453 UV/Visible [Vis] Spectrometer). The Br-PGR decomposition was recorded at the absorption band maximum (546 $\mathrm{nm}$ ) in the UV-Vis spectrum. Pure $\mathrm{TiO}_{2}$ thin film and $\mathrm{TiO}_{2} / \mathrm{ZnO}$ bi-layer film were used as reference catalysts in order to study the effect of microstructure on the catalytic behaviour. They were prepared on clear glass substrates with predeposited $\mathrm{ZnO}$ seed layer by using the identical sputtering parameters as those of the $\mathrm{ZnO} / \mathrm{TiO}_{2}$ composite nano-brush. The tests of photocatalytic decomposition of $\mathrm{Br}$-PGR dye
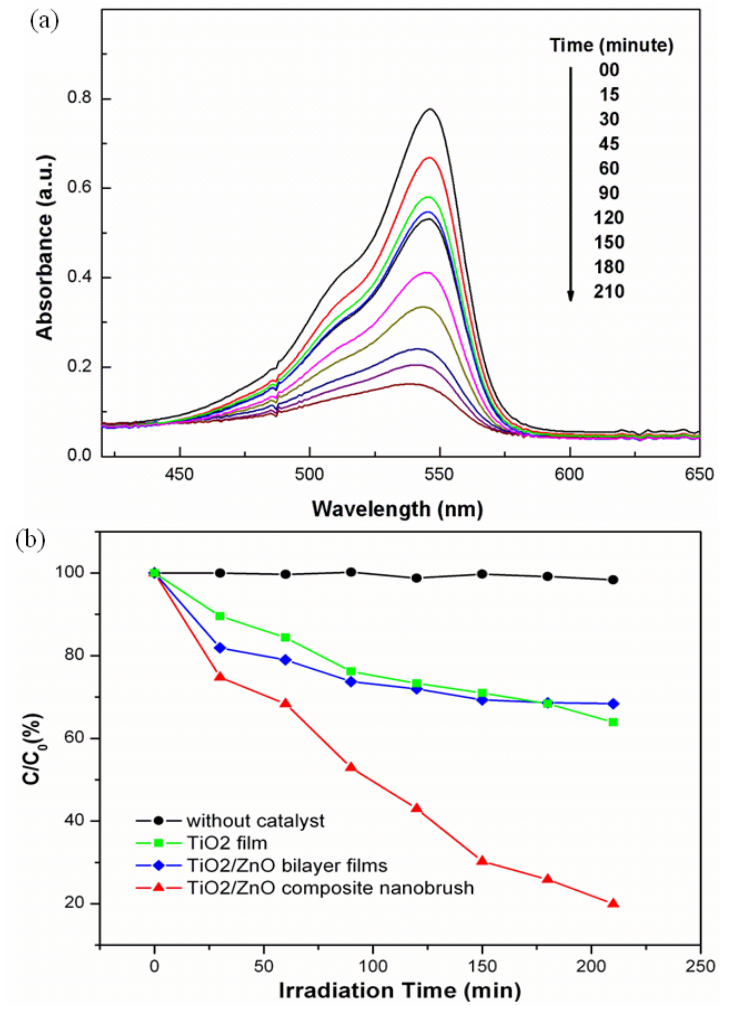

Fig. 8. (a) Photo-degradation of Bromo-Pyrogallol red (Br-PGR) using zinc oxide/titanium dioxide $\left(\mathrm{ZnO} / \mathrm{TiO}_{2}\right)$ composite nano-brush sample sputtered for 90 minutes; (b) temporal degradation rate of $\mathrm{Br}$-PGR with $\mathrm{ZnO} / \mathrm{TiO}_{2}$ composite nano-brush film (90 minutes), compared with the performance of sputtered $\mathrm{TiO}_{2}$ film and $\mathrm{TiO}_{2} / \mathrm{ZnO}$ bilayer film.

solution using these reference catalysts were conducted under the same experimental conditions as did with $\mathrm{ZnO} / \mathrm{TiO}_{2}$ composite nano-brush samples.

Figure $8(a)$ shows the temporal evaluation of UV-Vis spectrum changes accompanying the photo-degradation of $\mathrm{Br}$ PGR using the $\mathrm{ZnO} / \mathrm{TiO}_{2}$ composite nano-brush sample sputter deposited for 90 minutes. The Br-PGR dye initially showed a major absorption band at $546 \mathrm{~nm}$, gradually decreased in absorption and slightly shifted the band to the short wavelength with increasing irradiation time under the UV light. Fig. 8(b) shows the temporal degradation rate of $\mathrm{Br}$-PGR over $\mathrm{ZnO} / \mathrm{TiO}_{2}$ composite nano-brush (90 minutes) compared with $\mathrm{TiO}_{2}$ thin film and $\mathrm{TiO}_{2} / \mathrm{ZnO}$ bi-layer film. $\mathrm{C}_{0}$ and $\mathrm{C}$ are the equilibrium concentration of Br-PGR before and after UV irradiation, respectively.

As can be seen in Fig. 8(b), for the $\mathrm{ZnO} / \mathrm{TiO}_{2}$ composite nano-brush sample, the concentration of $\mathrm{Br}-\mathrm{PGR}$ is reduce to $19 \%$ after UV irradiation of 210 minutes, whereas the degradation effectiveness of the $\mathrm{TiO}_{2}$ film and $\mathrm{TiO}_{2} / \mathrm{ZnO}$ bi-layer film are $68 \%$ and $64 \%$, respectively. It is obvious that $\mathrm{ZnO} / \mathrm{TiO}_{2}$ composite nano-brush structure have a better photocatalytic property than $\mathrm{TiO}_{2}$ thin films coated either on glass substrate or on $\mathrm{ZnO}$ seeds layer. In addition, the blank Br-PGR sample without any catalyst shows almost no decomposition under the same UV irradiation condition.

An important factor contributing to the enhanced photocatalytic activity of $\mathrm{ZnO} / \mathrm{TiO}_{2}$ composite nano-brush nanos- 
tructure is that the special structure has obviously a much larger specific surface area compared to the simple layer deposited films. The large surface area comes from $\mathrm{ZnO}$ nanorods array and the covered nanosized $\mathrm{TiO}_{2}$ "hairs," which can supply a very high density of active site for surface reactions as well as a high interfacial charge carrier transfer. These factors are believed greatly beneficial for the enhancement of photocatalytic performance. In addition, the coupling of $\mathrm{TiO}_{2}$ and $\mathrm{ZnO}$ nanostructure could induce an extension of the light wavelength range, which increases the light absorption and decrease the photocatalytic reaction energy, therefore improving the photocatalytic activity [7], [29].

Another advantage of using the $\mathrm{ZnO} / \mathrm{TiO}_{2}$ composite nanobrush structure as catalyst is from the unique hierarchically core-brush structure, which can immobilize the $\mathrm{TiO}_{2}$ nanostructures on the surface of $\mathrm{ZnO}$ nanorods. Accordingly, there will be less separation and recovering issues when utilize $\mathrm{ZnO} / \mathrm{TiO}_{2}$ composite nano-brush in water or air purification process, which are currently a major obstacle that limited a wider application of nanostructured photocatalysts. So the $\mathrm{ZnO} / \mathrm{TiO}_{2}$ composite nano-brush structure may be used as an effective and recyclable photocatalyst for practical applications in the near future.

\section{2 $\mathrm{ZnO} / \mathrm{V}_{2} \mathrm{O}_{5}$ composite nano-lollipop array for 2,6-dichlorophenol degradation}

Session 2.2.3 reported that $\mathrm{ZnO} / \mathrm{N}_{2} \mathrm{O}_{5}$ composite core-shell nanostructures convert to the ordered $\mathrm{ZnO} / \mathrm{N}_{2} \mathrm{O}_{5}$ composite nano-"lollipop" array after annealing treatment. Tests also conducted to investigate the photocatalytic properties of this heterogeneous nanostructure.

The UV-Vis absorption property of the $\mathrm{V}_{2} \mathrm{O}_{5} / \mathrm{ZnO}$ composite nano-lollipops array was investigated by UV-Vis spectroscopy as shown in Fig. 9(a). The absorption of pure $\mathrm{ZnO}$ nanowire array shows a sharp edge at $\sim 380 \mathrm{~nm}$, which obviously correspond to its band edge absorption since the band gap of $\mathrm{ZnO}$ material is about $3.3 \mathrm{eV}$. For the as-prepared $\mathrm{V}_{2} \mathrm{O}_{5} / \mathrm{ZnO}$ composite core-shell structure, the absorption edge has a clear shift towards the long wavelength direction. While for the annealed sample with the nano-lollipops shape, the absorption edge becomes ambiguous. The average absorption for UV light weakens a little while the absorption in the range of visible light strengthens greatly, indicating the potential for the photocatalytic applications with visible light or natural sunlight.

Accordingly, we tested the photocatalytic activity of these $\mathrm{V}_{2} \mathrm{O}_{5} / \mathrm{ZnO}$ composite nanostructures by examining the decay reaction of 2,6-dichlorophenol (2,6-DCP) under the radiation of $420 \mathrm{~nm}$ light source. The initial concentration of 2,6-DCP solution was fixed at $10 \mathrm{mg} / \mathrm{L}$ with an initial $\mathrm{pH}$ at 7.0. The results are shown in Fig. 9(b). It can be observed that the photocatalytic activity of these $\mathrm{V}_{2} \mathrm{O}_{5} / \mathrm{ZnO}$ composites is quite good in terms of the degradation of 2,6-DCP. After 6 hours, more than $60 \%$ removal of 2,6-DCP was achieved while without the catalysts, less than $5 \%$ decomposition of 2,6-DCP could be observed.

It is interesting to note it appears that the annealing temperature has little effect on the photocatalytic performance of the $\mathrm{V}_{2} \mathrm{O}_{5} / \mathrm{ZnO}$ composite. The UV-Vis spectra in Fig. 9(a)
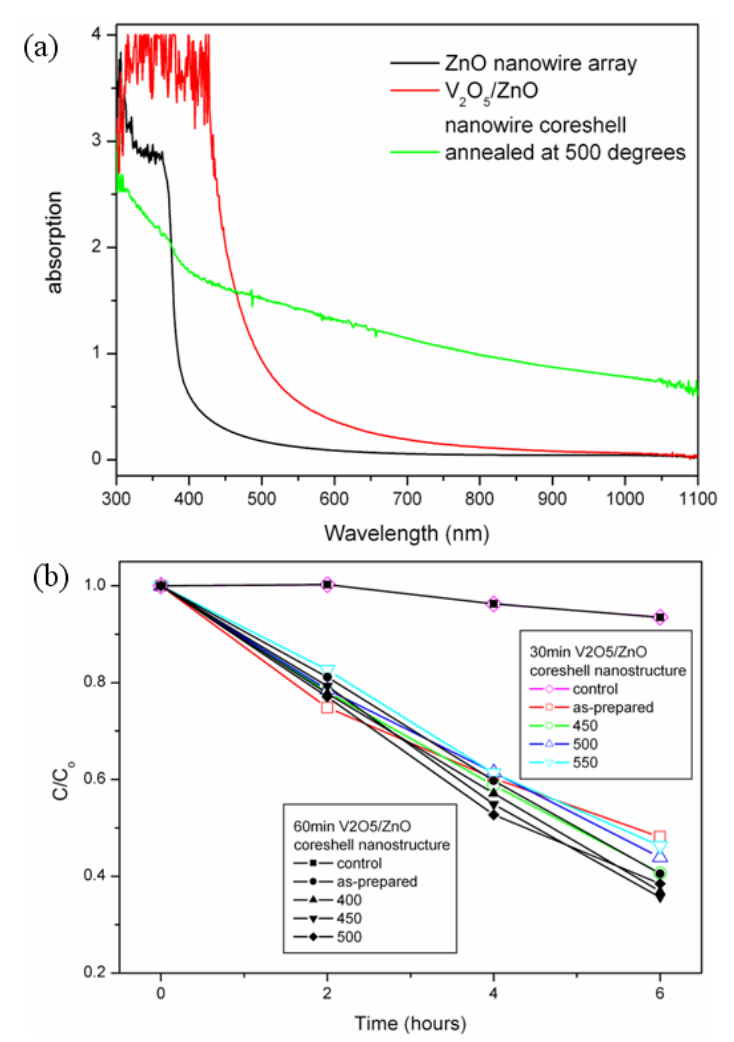

Fig. 9. (a) Ultraviolet visible spectra for pure zinc oxide ( $\mathrm{ZnO})$ nanowire array, as-deposited vanadium pentoxide $\left(\mathrm{V}_{2} \mathrm{O}_{5}\right) / \mathrm{ZnO}$ core-shell sample and the $\mathrm{V}_{2} \mathrm{O}_{5} / \mathrm{ZnO}$ nano-lollipops array after annealed at $500^{\circ} \mathrm{C}$; (b) The concentration of 2,6-dichlorophenol solution as the function of irradiation time by using $\mathrm{V}_{2} \mathrm{O}_{5} / \mathrm{ZnO}$ composite nanostructures as catalyst.

show the annealed sample has a relatively high absorption over the visible light range from 500 to $800 \mathrm{~nm}$. The photocatalytic light spectra centered at $420 \mathrm{~nm}$, however, contain mainly photos with wavelength ranging from 400 to $500 \mathrm{~nm}$ (data are not shown). Thus the annealing treatment could not demonstrate much influence on the photocatalytic activity of these $\mathrm{V}_{2} \mathrm{O}_{5} / \mathrm{ZnO}$ composites. We believe that the annealed samples may have better performance under the visible light at the wavelength longer than $500 \mathrm{~nm}$.

Furthermore, we found that the annealed composite samples are much more stable and strong than those asdeposited samples. The as-deposited $\mathrm{V}_{2} \mathrm{O}_{5}$ layered samples with amorphous state are easily to flake off in solution from the substrates or from the surface of $\mathrm{ZnO}$ nanorods. Thus the as-deposited samples are not suitable for long-term use or reuse, while the annealed $\mathrm{V}_{2} \mathrm{O}_{5} / \mathrm{ZnO}$ lollipop-array sample are quite strong and stable after several times tests. The next step we will test the phtocatalysis performance for the annealed heterogeneous nano-lollipops $\mathrm{V}_{2} \mathrm{O}_{5} / \mathrm{ZnO}$ array under visible light with longer wavelength or even with natural sunlight.

\section{CONCLUSIONS}

We have reviewed our recent work on $\mathrm{ZnO}, \mathrm{TiO}_{2}$ and $\mathrm{V}_{2} \mathrm{O}_{5}$ 
related composite nanostructural materials including the preparation, characterization, microstructure and the possible photocatalytic applications for decomposition of organic chemicals. Combined with hydrothermal growth, magnetron sputtering and thermal treatment, different and complex integrated hierarchical structures at nanoscale and low dimension have been prepared. These processing techniques are relatively easy and cheap, providing a convenient route for various composite nanostructures fabrication in the future. It is interesting to see that these composite samples show much improved optoelectronic properties and superior photocatalytic performances compared to the single oxide or simple layered oxide films.

Transition metal oxides with semiconductor nature attract great attention in recent years due to their special electronic and chemical properties. These oxides can often be made as low dimensional nanostructured composites such as nanowires, nanorods and core-shell structures. These types of nanostructures frequently show much improved and/or special electronic and optical properties because of the coupling effect between the different compounds as well as the enlarged surface areas. The mechanisms of these coupling effects are far from well understood. Research in this area is of both scientific and applied significance.

\section{ACKNOWLEDGEMENTS}

This work was partially supported by a Marsden Grant, a Collaboration Research Project with KACST Saudi Arabia (Dr. Ahmed Alyamani), and a Synchrotron Seed funding from New Zealand Synchrotron Group Ltd (the Royal Society of NZ). The authors would like to thank the group members especially X-D Yan, R-Q Chen, and J. Han for their work on ZnO and related topics, and staff members in the Department of Chemical \& Materials Engineering and the Research Center for Surface and Materials Science at the University of Auckland for their technical assistance.

\section{REFERENCES}

[1] X. Y. Kong and Z. L. Wang, Nano Lett. 3, 1625 (2003) [DOI: 10.1021/nl034463p].

[2] J. Bao, M. A. Zimmler, F. Capasso, X. Wang, and Z. F. Ren, Nano Lett. 6, 1719 (2006) [DOI: 10.1021/nlo61080t].

[3] R. Bardhan, H. Wang, F. Tam, and N. J. Halas, Langmuir 23, 5843 (2007) [DOI: 10.1021/la070146C].

[4] K. S. Leschkies, A. G. Jacobs, D. J. Norris, and E. S. Aydil, Appl. Phys. Lett. 95, 193103 (2009) [DOI: 10.1063/1.3258490].

[5] Y. K. Kim, S. J. Park, J. P. Koo, G. T. Kim, S. H. Hong, and J. S. Ha, Nanotechnology 18, 015304 (2007) [DOI: 10.1088/0957-4484/ 18/1/015304].

[6] X. W. Sun, J. Z. Huang, J. X. Wang, and Z. Xu, Nano Lett. 8, 1219 (2008) [DOI: 10.1021/nlo80340z].

[7] Z. L. Wang, ACS Nano 2, 1987 (2008) [DOI: 10.1021/nn800631r].

[8] B. Yan, L. Liao, Y. You, X. Xu, Z. Zheng, Z. Shen, J. Ma, L. Tong, and T. Yu, Adv. Mater. 21, 2436 (2009) [DOI: 10.1002/adma. 200803684].

[9] R. Wang, C. Ruan, D. Kanayeva, K. Lassiter, and Y. Li, Nano Lett. 8, 2625 (2008) [DOI: 10.1021/nlo80366q].
[10] T. S. Kang, A. P. Smith, B. E. Taylor, and M. F. Durstock, Nano Lett. 9, 601 (2009) [DOI: 10.1021/nl802818d].

[11] A. Vomiero, I. Concina, M. M. Natile, E. Comini, G. Faglia, M. Ferroni, I. Kholmanov, and G. Sberveglieri, Appl. Phys. Lett. 95, 193104 (2009) [DOI: 10.1063/1.3257370].

[12] W. Gao and Z. Li, Int. J. Nanotechnol. 6, 245 (2009) [DOI: 10.1504/IJNT.2009.022917].

[13] P. Oliveira, M. L. Rojas-Cervantes, A. M. Ramos, I. M. Fonseca, A. M. B. do Rego, and J. Vital, Catal. Today 118, 307 (2006) [DOI: 10.1016/j.cattod.2006.07.032].

[14] E. Zhan, Y. Li, J. Liu, X. Huang, and W. Shen, Catal. Commun. 10, 2051 (2009) [DOI: 10.1016/j.catcom.2009.07.029].

[15] C. Bluthardt, C. Fink, K. Flick, A. Hagemeyer, M. Schlichter, and A. Volpe Jr., Catal. Today 137, 132 (2008) [DOI: 10.1016/ j.cattod.2008.04.045].

[16] S. Rackauskas, A. G. Nasibulin, H. Jiang, Y. Tian, V. I. Kleshch, J. Sainio, E. D. Obraztsova, S. N. Bokova, A. N. Obraztsov, and E. I. Kauppinen, Nanotechnology 20, 165603 (2009) [DOI: 10.1088/ 0957-4484/20/16/165603].

[17] F. Li, D. I. Son, S. H. Cho, W. T. Kim, and T. W. Kim, Nanotechnology 20, 155202 (2009) [DOI: 10.1088/0957-4484/ 20/15/155202].

[18] F. Li, S. H. Cho, D. I. Son, T. W. Kim, S. K. Lee, Y. H. Cho, and S. H. Jin, Appl. Phys. Lett. 94, 111906 (2009) [DOI: 10.1063/1.3098400].

[19] H. Zeng, X. Xu, Y. Bando, U. K. Gautam, T. Zhai, X. Fang, B. Liu, and D. Golberg, Adv. Funct. Mater. 19, 3165 (2009) [DOI: 10.1002/adfm.200900714].

[20] Z. W. Pan, Z. R. Dai, and Z. L. Wang, Science 291, 1947 (2001) [DOI: 10.1126/science.1058120].

[21] X. Y. Kong, Y. Ding, R. Yang, and Z. L. Wang, Science 303, 1348 (2004) [DOI: 10.1126/science.1092356].

[22] P. X. Gao, Y. Ding, W. Mai, W. L. Hughes, C. Lao, and Z. L. Wang, Science 309, 1700 (2005) [DOI: 10.1126/science.1116495].

[23] S. W. Choi, J. Y. Park, and S. S. Kim, Nanotechnology 20, 465603 (2009) [DOI: 10.1088/0957-4484/20/46/465603].

[24] X. Zhang, Y. Chen, C. Jia, Y. Su, Q. Li, L. liu, T. Gou, and M. Wei, J. Phys. Chem. C 113, 13689 (2009) [DOI: 10.1021/ jp903713g].

[25] R. C. Wang and H. Y. Lin, Appl. Phys. A 95, 813 (2009) [DOI: 10.1007/s00339-009-5079-4].

[26] F. Xu, V. Volkov, Y. Zhu, H. Bai, A. Rea, N. V. Valappil, W. Su, X. Gao, I. L. Kuskovsky, and H. Matsui, J. Phys. Chem. C 113, 19419 (2009) [DOI: 10.1021/jpg03813h].

[27] M. Agrawal, S. Gupta, A. Pich, N. E. Zafeiropoulos, and M. Stamm, Chem. Mater. 21, 5343 (2009) [DOI: 10.1021/cm9028098].

[28] J. Y. Park, S. W. Choi, J. W. Lee, C. M. Lee, and S. S. Kim, J. Am. Ceram. Soc. 92, 2551 (2009) [DOI: 10.1111/j.1551-2916.2009. 03270.x].

[29] Y. Yang, D. S. Kim, Y. Qin, A. Berger, R. Scholz, H. Kim, M. Knez, and U. Gösele, J. Am. Chem. Soc. 131, 13920 (2009) [DOI: 10.1021/jago6120a].

[30] L. E. Greene, M. Law, B. D. Yuhas, and P. Yang, J. Phys. Chem. C 111, 18451 (2007) [DOI: 10.1021/jpo77593l].

[31] D. Mustafa, D. Biggemann, J. Wu, J. L. Coffer, and L. R. Tessler, Superlattices Microstruct. 42, 403 (2007) [DOI: 10.1016/j.spmi. 2007.04.042].

[32] S. Z. Li, C. L. Gan, H. Cai, C. L. Yuan, J. Guo, P. S. Lee, and J. Ma, Appl. Phys. Lett. 90, 263106 (2007) [DOI: 10.1063/1.2752020].

[33] V. E. Kaydashev, E. M. Kaidashev, M. Peres, T. Monteiro, M. R. Correia, N. A. Sobolev, L. C. Alves, N. Franco, and E. Alves, J. Appl. Phys. 106, 093501 (2009) [DOI: 10.1063/1.3253572].

[34] C. W. Zou, X. D. Yan, J. Han, R. Q. Chen, J. M. Bian, E. Haemmerle, and W. Gao, Chem. Phys. Lett. 476, 84 (2009) [DOI: 10.1016/ j.cplett.2009.06.024].

[35] X. Yan, Z. Li, R. Chen, and W. Gao, Cryst. Growth Des. 8, 2406 (2008) [DOI: 10.1021/cg7012599].

[36] C. W. Zou, X. D. Yan, J. Han, R. Q. Chen, and W. Gao, J. Phys. D: Appl. Phys. 42, 145402 (2009) [DOI: 10.1088/0022-3727/42/14/ 145402]. 
[37] F. Zhou, X. Zhao, Y. Liu, C. Yuan, and L. Li, Eur. J. Inorg. Chem. 2008, 2506 (2008) [DOI: 10.1002/ejic.200800148].

[38] K. Takahashi, Y. Wang, and G. Cao, Appl. Phys. Lett. 86, 053102 (2005) [DOI: 10.1063/1.1857087].

[39] R. T. R. Kumar, E. McGlynn, M. Biswas, R. Saunders, G. Trolliard, B. Soulestin, J. R. Duclere, J. P. Mosnier, and M. O. Henry, J. Appl. Phys. 104, 084309 (2008) [DOI: 10.1063/1.2996279].

[40] Z. Zhu, T. L. Chen, Y. Gu, J. Warren, and R. M. Osgood, Chem. Mater. 17, 4227 (2005) [DOI: 10.1021/cm050584+].

[41] W. Lee, M. C. Jeong, and J. M. Myoung, Acta Mater. 52, 3949 (2004) [DOI: 10.1016/j.actamat.2004.05.010].

[42] Z. Wang, X. Liu, J. Gong, H. Huang, S. Gu, and S. Yang, Cryst. Growth Des. 8, 3911 (2008) [DOI: 10.1021/cg800588q].

[43] M. Willander, O. Nur, Q. X. Zhao, L. L. Yang, M. Lorenz, B. Q. Cao, J. Z. Perez, C. Czekalla, G. Zimmermann, M. Grundmann, A. Bakin, A. Behrends, M. Al-Suleiman, A. El-Shaer, A. C. Mofor, B. Postels, A. Waag, N. Boukos, A. Travlos, H. S. Kwack, J. Guinard, and D. L. S. Dang, Nanotechnology 20, 332001 (2009) [DOI: 10.1088/09574484/20/33/332001].

[44] S. Y. Zhan, C. Z. Wang, K. Nikolowski, H. Ehrenberg, G. Chen, and Y. J. Wei, Solid State Ionics 180, 1198 (2009) [DOI: 10.1016/ j.ssi.2009.05.020].

[45] E. Strelcov, Y. Lilach, and A. Kolmakov, Nano Lett. 9, 2322 (2009) [DOI: 10.1021/nl900676n].

[46] J. M. Velazquez and S. Banerjee, Small 5, 1025 (2009) [DOI: 10.1002/smll.200801278].

[47] M. G. Willinger, G. Neri, E. Rauwel, A. Bonavita, G. Micali, and N. Pinna, Nano Lett. 8, 4201 (2008) [DOI: 10.1021/nl801785b].

[48] A. M. Glushenkov, V. I. Stukachev, M. F. Hassan, G. G. Kuvshinov, H. K. Liu, and Y. Chen, Cryst. Growth Des. 8, 3661 (2008) [DOI: $10.1021 / \mathrm{cg} 800257 \mathrm{~d}]$.

[49] Y. Wang, Z. Zhang, Y. Zhu, Z. Li, R. Vajtai, L. Ci, and P. M. Ajayan, ACS Nano 2, 1492 (2008) [DOI: 10.1021/nn800223s].

[50] W. G. Menezes, D. M. Reis, T. M. Benedetti, M. M. Oliveira, J. F. Soares, R. M. Torresi, and A. J. G. Zarbin, J. Colloid Interface Sci. 337, 586 (2009) [DOI: 10.1016/j.jcis.2009.05.050].

[51] A. Dhayal Raj, T. Pazhanivel, P. Suresh Kumar, D. Mangalaraj, D. Nataraj, and N. Ponpandian, Curr. Appl. Phys. 10, 531 (2010) [DOI: 10.1016/j.cap.2009.07.015].

[52] D. Liu, Y. Liu, B. B. Garcia, Q. Zhang, A. Pan, Y. H. Jeong, and G. Cao, J. Mater. Chem. 19, 8789 (2009) [DOI: 10.1039/b914436f].

[53] S. Putluru, A. Riisager, and R. Fehrmann, Catal. Lett. 133, 370 (2009) [DOI: 10.1007/s10562-009-0176-8].

[54] S. L. Chou, J. Z. Wang, J. Z. Sun, D. Wexler, M. Forsyth, H. K. Liu, D. R. MacFarlane, and S. X. Dou, Chem. Mater. 20, 7044 (2008) [DOI: 10.1021/cm801468q].

[55] M. C. Wu and C. S. Lee, J. Solid State Chem. 182, 2285 (2009) [DOI: 10.1016/j.jssc.2009.05.042].

[56] X. K. Hu, D. K. Ma, J. B. Liang, S. L. Xiong, J. Y. Li, and Y. T. Qian, Chem. Lett. 36, 560 (2007) [DOI: 10.1246/cl.2007.560].

[57] C. O. Avellaneda, Mater. Sci. Eng., B 138, 118 (2007) [DOI: 10.1016/j.mseb.2006.06.007].

[58] F. N. Dultsev, L. L. Vasilieva, S. M. Maroshina, and L. D. Pokrovsky, Thin Solid Films 510, 255 (2006) [DOI: 10.1016/ j.tsf.2005.12.264].

[59] A. Sidorov, O. Vinogradova, V. Lyubimov, and A. Nashchekin,
Tech. Phys. Lett. 34, 133 (2008) [DOI: 10.1007/s11455-008-2014-6].

[60] C. Piccirillo, R. Binions, and I. P. Parkin, Chem. Vap. Deposition 13, 145 (2007) [DOI: 10.1002/cvde.200606540].

[61] C. W. Zou, X. D. Yan, D. A. Patterson, E. A. C. Emanuelsson, J. M. Bian, and W. Gao, CrystEngComm (2010 In press) [DOI: 10.1039/b916614a].

[62] K. H. Ko, Y. C. Lee, and Y. J. Jung, J. Colloid Interface Sci. 283, 482 (2005) [DOI: 10.1016/j.jcis.2004.09.009].

[63] S. J. Roh, R. S. Mane, S. K. Min, W. J. Lee, C. D. Lokhande, and S. H. Han, Appl. Phys. Lett. 89, 253512 (2006) [DOI: 10.1063/ 1.2410240].

[64] C. H. Ku and J. J. Wu, Appl. Phys. Lett. 91, 093117 (2007) [DOI: 10.1063/1.2778454].

[65] C. Kim, K. S. Kim, H. Y. Kim, and Y. S. Han, J. Mater. Chem. 18, 5809 (2008) [DOI: 10.1039/b805091k].

[66] M. Law, L. E. Greene, A. Radenovic, T. Kuykendall, J. Liphardt, and P. Yang, J. Phys. Chem. B 110, 22652 (2006) [DOl: 10.1021/jp0648644].

[67] S. Wu, H. Han, Q. Tai, J. Zhang, B. L. Chen, S. Xu, C. Zhou, Y. Yang, H. Hu, and X. Z. Zhao, Appl. Phys. Lett. 92, 122106 (2008) [DOI: 10.1063/1.2903105].

[68] S. S. Kim, J. H. Yum, and Y. E. Sung, J. Photochem. Photobiol. A: Chem. 171, 269 (2005) [DOI: 10.1016/j.jphotochem.2004.10. 019].

[69] J. M. Wu, H. C. Shih, W. T. Wu, Y. K. Tseng, and I. C. Chen, J. Cryst. Growth 281, 384 (2005) [DOI: 10.1016/j.jcrysgro.2005.04. 018].

[70] Y. L. Chueh, C. H. Hsieh, M. T. Chang, L. J. Chou, C. S. Lao, J. H. Song, J. Y. Gan, and Z. L. Wang, Adv. Mater. 19, 143 (2007) [DOI: 10.1002/adma.200601830].

[71] Y. Lei, L. D. Zhang, G. W. Meng, G. H. Li, X. Y. Zhang, C. H. Liang, W. Chen, and S. X. Wang, Appl. Phys. Lett. 78, 1125 (2001) [DOI: 10.1063/1.1350959].

[72] Y. Hu, Z. Li, Z. Zhang, and D. Meng, Appl. Phys. Lett. 94, 103107 (2009) [DOI: 10.1063/1.3095502].

[73] Y. Wang, Z. Li, X. Sheng, and Z. Zhang, J. Chem. Phys. 126, 164701 (2007) [DOI: 10.1063/1.2722746].

[74] T. Minami, T. Utsubo, T. Miyata, and Y. Suzuki, Thin Solid Films 445, 377 (2003) [DOI: 10.1016/s0040-6090 (03)01186-6].

[75] K. K. Kim, S. D. Lee, H. S. Kim, J. C. Park, S. N. Lee, Y. S. Park, S. J. Park, and S. W. Kim, Appl. Phys. Lett. 94, 071118 (2009) [DOI: 10.1063/1.3077606].

[76] J. Zhong, H. Chen, G. Saraf, Y. Lu, C. K. Choi, J. J. Song, D. M. Mackie, and H. Shen, Appl. Phys. Lett. 90, 203515 (2007) [DOI: 10.1063/1.2741052].

[77] M. Kurzawa, I. Rychlowska-Himmel, M. Bosacka, and A. BlonskaTabero, J. Therm. Anal. Calorim. 64, 1113 (2001) [DOI: 10.1023/ A:1011524424682].

[78] S. T. Tan, B. J. Chen, X. W. Sun, W. J. Fan, H. S. Kwok, X. H. Zhang, and S. J. Chua, J. Appl. Phys. 98, 013505 (2005) [DOI: 10.1063/1.1940137].

[79] X. Zhang, D. Liu, L. Zhang, W. Li, M. Gao, W. Ma, Y. Ren, Q. Zeng, Z. Niu, W. Zhou, and S. Xie, J. Mater. Chem. 19, 962 (2009) [DOI: 10.1039/b815518f].

[80] H. H. Patterson, J. Cheng, S. Despres, M. Sunamoto, and M. Anpo, J. Phys. Chem. 95, 8813 (1991) [DOI: 10.1021/j100175a072].

[81] S. G. Zhang, S. Higashimoto, H. Yamashita, and M. Anpo, J. Phys. Chem. B 102, 5590 (1998) [DOI: 10.1021/jpg8123or]. 